\title{
Nearshore sandbar migration
}

\author{
Steve Elgar \\ Woods Hole Oceanographic Institution, Woods Hole, Massachusetts
}

Edith L. Gallagher

Department of Oceanography, Naval Postgraduate School, Monterey, California

R. T. Guza

Center for Coastal Studies, Scripps Institution of Oceanography, La Jolla, California

\begin{abstract}
Field observations suggest that onshore sandbar migration, observed when breaking-wave-driven mean flows are weak, may be related to the skewed fluid accelerations associated with the orbital velocities of nonlinear surface waves. Large accelerations (both increases and decreases in velocity magnitudes), previously suggested to increase sediment suspension, occur under the steep wave faces that immediately precede the maximum onshore-directed orbital velocities. Weaker accelerations occur under the gently sloping rear wave faces that precede the maximum offshore-directed velocities. The timing of strong accelerations relative to onshore flow is hypothesized to produce net onshore sediment transport. The observed acceleration skewness, a measure of the difference in the magnitudes of accelerations under the front and rear wave faces, is maximum near the sandbar crest. The corresponding cross-shore gradients of an acceleration-related onshore sediment transport would cause erosion offshore and accretion onshore of the bar crest, consistent with the observed onshore migration of the bar crest. Furthermore, the observations and numerical simulations of nonlinear shallow water waves show that the region of strongly skewed accelerations moves shoreward with the bar, suggesting that feedback between waves and evolving morphology can result in continuing onshore bar migration.
\end{abstract}

\section{Introduction}

Sandbars are important morphological features of beaches, and changes in their position and height are a primary source of beach profile variability [Lippmann and Holman, 1990]. Bars affect nearshore waves and circulation, both of which cause sediment transport and morphological evolution, including beach erosion and accretion. Cross-shore movement of sandbars may be important for artificial beach nourishment [Douglass, 1994] and the transport of sediment-bound pollutants [Short et al., 1996] and biota [Jumars and Nowell, 1984]. During storms, intense wave breaking on the bar crest drives strong offshore-directed, near-bottom flows (undertow) that result in offshore bar migration [Thornton et al., 1996; Gallagher et al., 1998]. Beaches eroded by storms are replenished at least partially by onshore transport and bar migration during less energetic conditions [Aubrey, 1979]. However, the causes of shoreward bar migration are not known. Laboratory [Madsen, 1974; Nielson, 1992] and field [Hanes and Huntley, 1986; Osborne and Greenwood, 1993; Jaffee and Rubin, 1996] studies suggest that fluid ac-

Copyright 2001 by the American Geophysical Union.

Paper number $2000 \mathrm{JC} 000389$.

0148-0227/01/2000JC000389\$09.00 celerations, as well as fluid velocities, determine sediment transport. Here, field observations are presented that link onshore sandbar migration with the cross-shore variation of fluid acceleration skewness. Additionally, the observations and numerical simulations of shallow water waves show that the region of strongly skewed accelerations moves shoreward with the bar, suggesting that feedback between waves and evolving morphology can result in continuing onshore bar migration when mean flows are weak.

\section{Sandbar Migration}

Offshore sandbar migration during storms results from feedback between breaking-wave-driven undertow and bathymetric change [Thornton et al., 1996; Gallagher et al., 1998]. Observations on the North Carolina coast show that undertow is maximum just onshore of the sandbar crest [ $\mathrm{Gal}$ lagher et al., 1998; Feddersen et al., 1998]. As the bar crest moves offshore, so does the location of the maximum undertow. Assuming no gradients in alongshore transport, conservation of sediment yields $d Q / d x \propto d h / d t$, where $Q$ is the time-averaged (over many wave periods) cross-shore volume sediment transport per unit beach width per unit time (units of length ${ }^{2}$ time $^{-1}$ ), $x$ is the cross-shore coordinate, $h$ is the elevation of the seafloor (relative to mean sea level), 


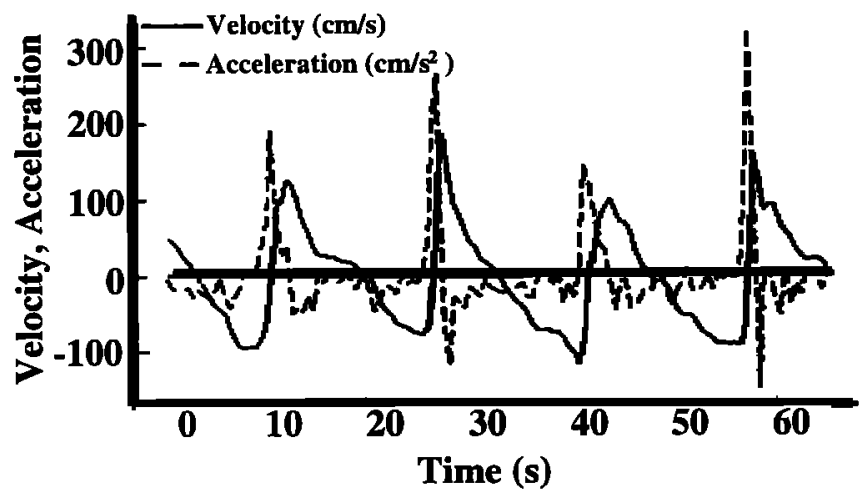

Figure 1. Near-bottom cross-shore velocity (solid curve) and acceleration (dashed curve) versus time for asymmetric waves observed in $1.5-\mathrm{m}$ water depth near the seaward edge of the surf zone. Strong onshore (positive) accelerations are associated with the steep front faces of the waves (propagating toward the left) where the flow changes rapidly from maximum offshore-directed (negative) to maximum onshore-directed (positive) velocities. Under the steep front face the offshore flow decelerates rapidly, followed by strong acceleration of the onshore flow.

and $t$ is time. Predictions of bathymetric change $(d h / d t)$ based on models for $Q$ that include both mean and oscillatory flows suggest that the offshore bar migration observed during storms is driven primarily by cross-shore gradients of undertow (and associated gradients of $Q$ ) that result in erosion onshore and accretion offshore of the sandbar crest [Thornton et al., 1996; Gallagher et al., 1998].

The onshore transport and sandbar migration observed between storms when mean currents on the bar crest are weak have been hypothesized to result from the skewed orbital velocities of nonlinear shallow water waves. With $Q$ assumed to depend nonlinearly on the instantaneous orbital velocity, more sediment is transported by the large onshoredirected velocities under the sharply peaked crests of skewed waves than by the longer-duration, but smaller, offshoredirected velocities under their broad, flat troughs [Bowen, 1980; Bailard, 1981]. Although skewed velocities may be important in some circumstances [Trowbridge and Young, 1989; Douglass, 1994], velocity skewness-based models fail to predict the onshore bar migration observed near the shoreline and in the surf zone [Roelvink and Stive, 1989; Wright et al., 1991; Thornton et al., 1996; Rakha et al., 1997; Gallagher et al., 1998].

As waves shoal, their shapes and orbital velocities evolve from skewed profiles in intermediate water depths to asymmetric shapes with pitched forward, steep front faces and more gently sloping rear faces just prior to breaking and in the surf zone (e.g., bores). Onshore- and offshore-directed velocities are approximately equal in purely asymmetric wave (i.e., waves with zero velocity skewness), and thus over a wave period there is no net orbital velocity-driven transport. Although the orbital velocity skewness is not zero in the nearshore, usually it is much smaller than the orbital velocity asymmetry. Asymmetrical wave orbital velocities result in skewed fluid accelerations (both increases and decreases in velocity magnitudes) [Elgar et al., 1988], with larger accelerations under the steep front face of the wave (immediately preceding maximum onshore-directed orbital velocities) than under the gently sloping rear face (preceding the maximum offshore-directed orbital velocities) (Figure 1). Thus, if fluid accelerations temporarily increase the amount of sediment in motion [Madsen, 1974; Hallermeier, 1982; Hanes and Huntley, 1986; Nielson, 1992; Osborne and Greenwood, 1993; Jaffee and Rubin, 1996], the timing of strong accelerations relative to onshore orbital velocities in asymmetrical waves could result in net shoreward transport.

\section{Observations}

Nearly continuous observations of waves, near-bottom velocities, and bathymetry obtained for 45 days on a sandy, barred beach near Duck, North Carolina, are used here to investigate the relationship between wave orbital velocity and acceleration and sandbar location and migration. The observations were made along a cross-shore transect (Figure 2) extending from near the shoreline (mean sediment grain size $\approx 0.30 \mathrm{~mm}$ ) to approximately 4 -m water depth (grain size $\approx 0.15 \mathrm{~mm}$ ) [Elgar et al., 1997; Gallagher et al., 1998; Feddersen et al., 1998]. The 11 bidirectional electromagnetic current meters were adjusted vertically as the bathymetry evolved to maintain about $50-\mathrm{cm}$ elevation above the seafloor. Acceleration time series were computed by differentiating the velocity in the frequency domain and inverse Fourier transforming. Skewness and asymmetry were calculated as the mean cube of the demeaned time series and Hilbert-transformed time series, respectively, normalized by the variance [Elgar and Guza, 1985; Elgar, 1987]. Moments were estimated from 3-hour-long time series (sampled at $2 \mathrm{~Hz}$ ) by averaging moments calculated from 512-s low-passed-filtered (cutoff frequency of $0.3 \mathrm{~Hz}$ ) subrecords.

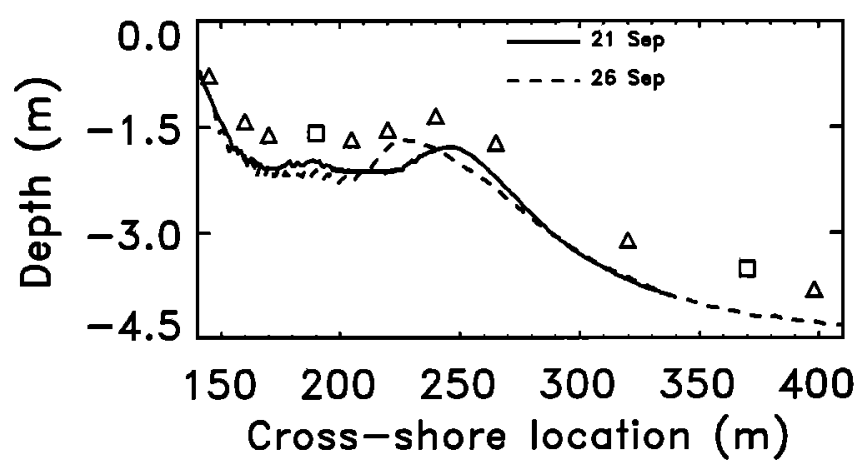

Figure 2. Instrument locations (symbols) and depth (relative to mean sea level) of the seafloor (curves) versus cross-shore location. Triangles are colocated current meters, pressure gauges, and sonar altimeters that continuously measure the seafloor location relative to a fixed frame [Gallagher et al., 1996]. Squares are colocated current meters and pressure gauges. The depth profiles were obtained with an amphibious vehicle at the beginning (solid curve) and end (dashed curve) of an onshore sandbar migration event in September 1994 near Duck, North Carolina. The shoreline fluctuated (owing to a $1-\mathrm{m}$ tide range) about cross-shore location equal to $125 \mathrm{~m}$. 


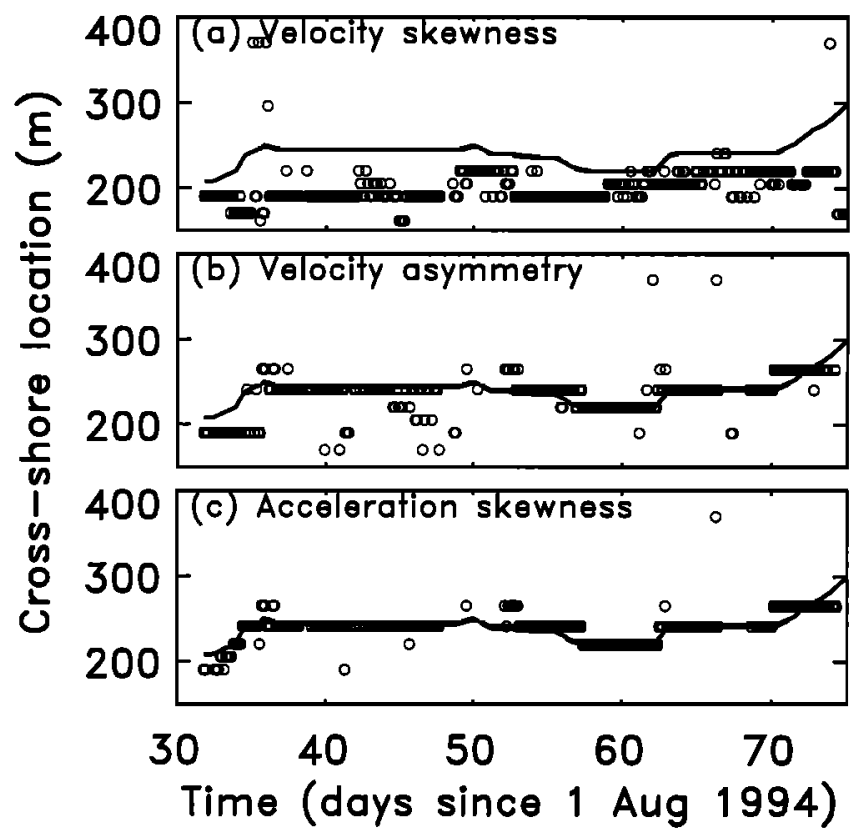

Figure 3. Cross-shore location (circles) of maxima of nearbottom orbital (a) velocity skewness, (b) velocity asymmetry, and (c) acceleration skewness versus time. The crossshore location of the crest of the sandbar is indicated by the solid curve in each panel.

The cross-shore location of the crest of the sandbar was estimated from spatially dense surveys conducted with an amphibious vehicle [Lee and Birkemeier, 1993] approximately biweekly for the first 30 days and daily for the last 15 days, combined with 3-hourly estimates of seafloor elevation from sonar altimeter measurements (Figure 2) [ $\mathrm{Gal}$ lagher et al., 1998]. An example of approximately 25-m onshore sandbar migration over a 5-day period is shown in Figure 2.

For the wide range of wave conditions during the field observations presented here [Gallagher et al., 1998; Feddersen et al., 1998], the location of the maximum of near-bottom cross-shore orbital velocity skewness usually was between the sandbar and the shoreline, and was not correlated with the location of the bar crest (Figure 3a). Although transport is not expected if the velocity variance is small even for large values of the skewness (a normalized quantity), the correlation between skewness and bar crest location was low for the wide range of wave (Plate la) and current conditions observed. Consequently, the corresponding cross-shore gradients in velocity skewness do not support the hypothesis that velocity skewness-driven sediment transport causes the observed bar migration.

In contrast, velocity asymmetry (Figure $3 b$ ) and the closely related acceleration skewness [Elgar and Guza, 1985; Elgar, 1987] (Figure 3c) are maximum near the sandbar crest. Large values of velocity asymmetry indicate pitched forward waves with steep front faces, gently sloping rear faces, and skewed accelerations (Figure 1). The spatial variation (Plate 1c) and corresponding cross-shore gradients (Plate 1d) of acceleration skewness are consistent with erosion offshore and accretion onshore of the bar crest if $Q$ is increased by strong accelerations or decelerations. In addition, the velocity asymmetry (Figure $3 \mathrm{~b}$ ) and acceleration skewness (Figure 3c and Plate 1c) maxima follow the bar crest, indicating that feedback between wave evolution and gradients in shoreward sediment transport (driven by gradients in skewed accelerations) may result in onshore sandbar migration when mean flows (Plate 1b) are weak.

To test further the relationship between wave orbital velocity and acceleration skewness and bar location, waves propagating between 3- and 1-m water depths over barred bathymetries were simulated numerically. Observations made over a 3-hour period in 3-m water depth (significant wave height was $75 \mathrm{~cm}$ ) during an onshore bar migration event (time equal to 54 days in Figure 3 and Plate 1, which is September 24, centered in time between the 2 profiles shown in Figure 2) were used to initialize a nonlinear Boussinesq wave model [Freilich and Guza, 1984]. Using the same initial conditions, the simulated wave field was computed for each of four fixed cross-shore depth profiles (Figure 4c).

For these waves and profiles the modeled orbital velocity skewness (Figure 4a) was not affected greatly by the location of the sandbar, but the cross-shore structure of the modeled acceleration skewness (Figure 4b) moved shoreward with the bar crest. Although these simulations of nonbreaking waves only qualitatively reproduce the cross-shore structure of the observed orbital velocity moments (which were affected by breaking), they are consistent with the observation (Figure $3 c$ and Plate $1 c$ ) that the acceleration skewness maximum follows the crest of the shoreward migrating sandbar.

\section{Conclusions}

Field observations and model simulations [Thornton et al., 1996; Gallagher et al., 1998] demonstrate that during storms strong undertow dominates net transport and bar migration is offshore (e.g., time equal to 33-36 and 70-75 days in Plate 1). In contrast, when cross-shore mean currents (Plate 1b) are relatively weak, but orbital velocities (proportional to wave height, Plate 1a) are not small, net transport associated with gradients in skewed fluid accelerations may dominate morphological change, resulting in onshore sandbar migration (e.g., time equal to 50-60 days in Plate 1). When both waves and mean currents are small, there is little transport and no morphological change (e.g., time equal to 37-48 days in Plate 1), even though the normalized acceleration skewness may be large.

Although the constitutive relationship between fluid velocity, fluid acceleration, and sediment motion is not known, the field observations presented here are consistent with the hypothesis that net onshore sediment transport and sandbar migration are related to cross-shore gradients in skewed fluid accelerations associated with pitched forward nonlinear waves. Consequently, incorporating the effects of fluid accelerations on sediment transport (e.g., by including both velocity and acceleration statistics in wave-averaged transport models or by including both velocity and acceleration time histories in instantaneous transport models) may result in improved models for nearshore bathymetric change that can predict both the undertow-driven offshore bar migration 


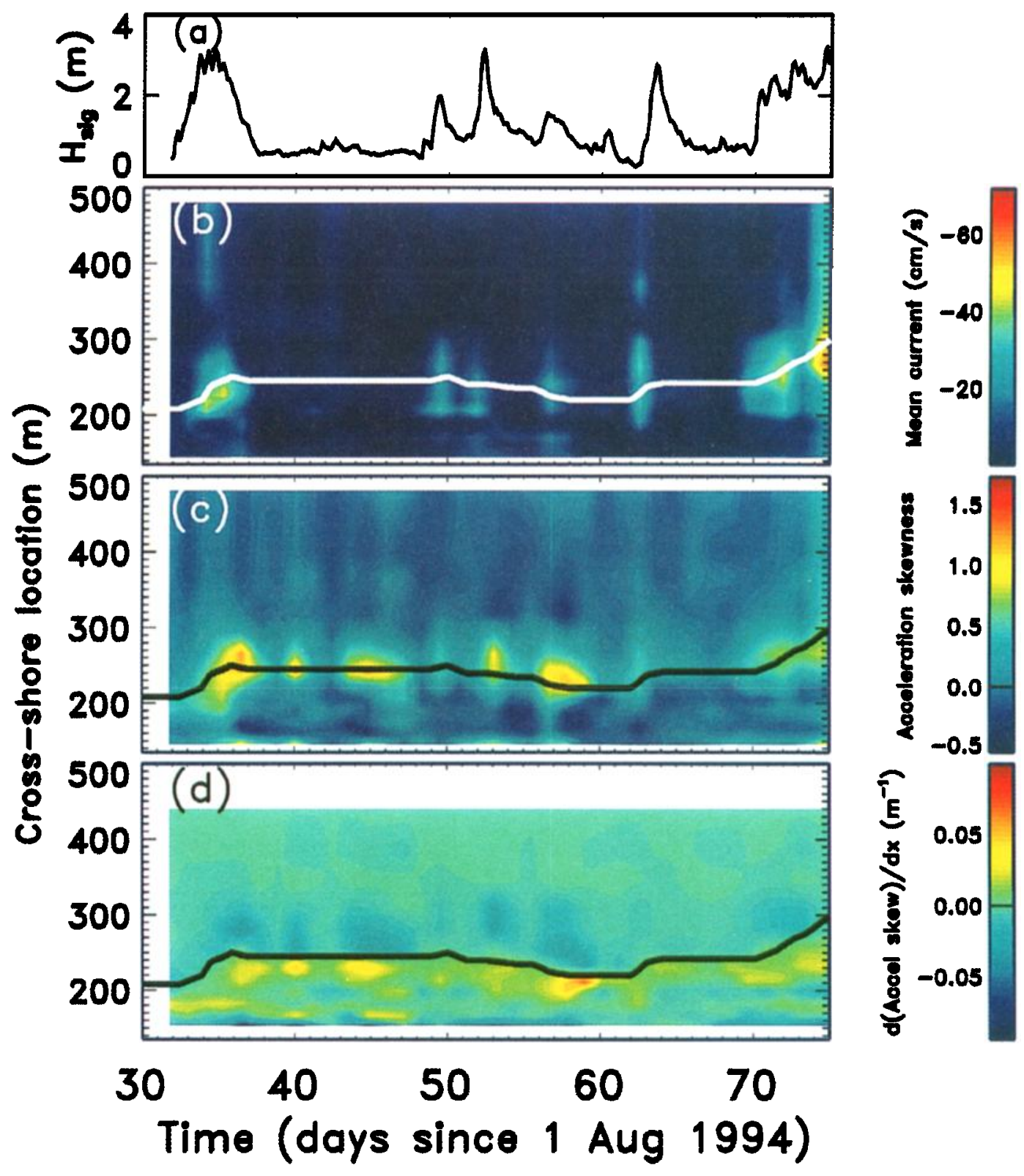

Plate 1. Observed wave and near-bottom cross-shore velocity and acceleration statistics. (a) Significant wave height (4 times the standard deviation of 3-hour long records of sea-surface elevation fluctuations in the frequency band between 0.01 and $0.3 \mathrm{~Hz}$ ) observed in $5-\mathrm{m}$ water depth versus time. Contours of (b) mean current (negative values are offshore-directed), (c) acceleration skewness, and (d) cross-shore gradient of the acceleration skewness as a function of cross-shore location and time. The cross-shore location of the sandbar crest is indicated by the solid curve on each contour plot. 

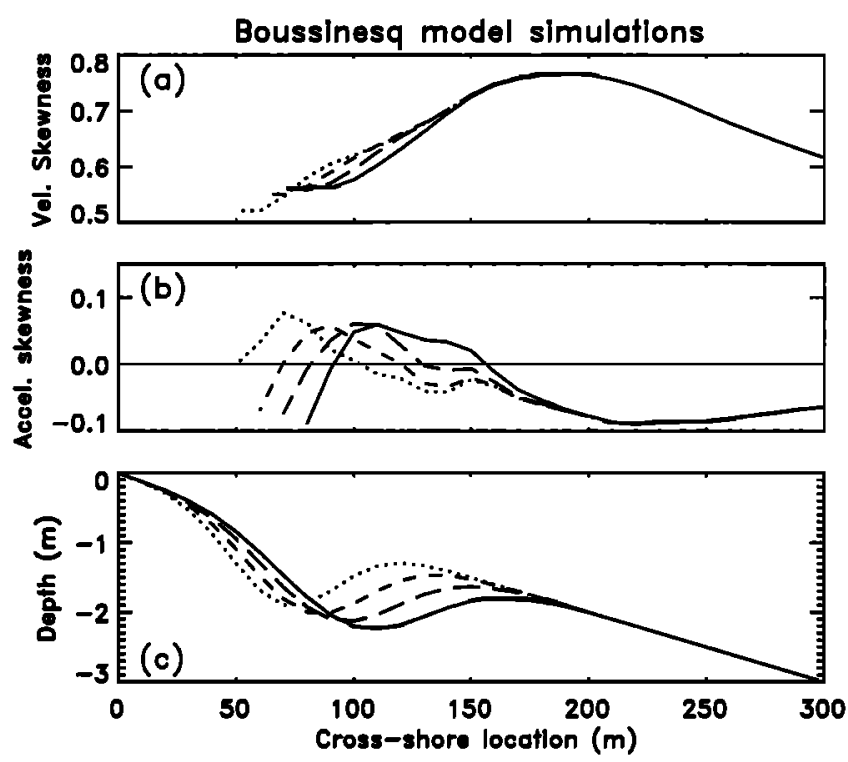

Figure 4. Modeled cross-shore orbital (a) velocity skewness and (b) acceleration skewness versus cross-shore location for the same initial conditions in 3-m water depth and (c) 4 different, fixed cross-shore depth profiles. The crest of the sandbar was displaced about $15 \mathrm{~m}$ shoreward in each successive profile, and the model was rerun.

observed during storms and the wave-driven onshore migration observed when mean cross-shore flows are weak.

Acknowledgments. We thank B. Raubenhemier, T.H.C. Herbers, the staff from the Center for Coastal Studies, Scripps Institution of Oceanography, and the U.S. Army Corps of Engineers Field Research Facility. Funding was provided by the Army Research Office, the Office of Naval Research, the National Research Council, the National Ocean Partnership Program, and the National Science Foundation. WHOI contribution 10070.

\section{References}

Aubrey, D., Seasonal patterns of onshore/offshore sediment movement, J. Geophys. Res., 84, 6347-6354, 1979.

Bailard, J., An energetics total load sediment transport model for a plane sloping beach, J. Geophys. Res., 86, 10,938-10,954, 1981.

Bowen, A., Simple models of nearshore sedimentation; beach profiles and longshore bars, in: The Coastline of Canada, S.B. McCann, ed. Geol. Surv. Can., 80-10, 1-11, 1980.

Douglass, S., Estimating landward migration of nearshore constructed sand mounds, J. Waterw. Port Coastal Ocean Eng., 121, 245-250, 1994.

Elgar, S., Relationships involving third moments and bispectra of a harmonic process, IEEE Trans. Acoust. Speech Signal Process. 35, 1725-1726, 1987.

Elgar, S., and R.T. Guza, Observations of bispectra of shoaling surface gravity waves, J. Fluid Mech., 161, 425-448, 1985.

Elgar, S., R.T. Guza, and M. Freilich, Eulerian measurements of horizontal accelerations in shoaling gravity waves, $J$. Geophys. Res., 93, 9261-9269, 1988.

Elgar, S., R.T. Guza, B. Raubenheimer, T.H.C. Herbers, and E. Gallagher, Spectral evolution of shoaling and breaking waves on a barred beach, J. Geophys. Res., 102, 15,797-15,805, 1997.
Feddersen, F., R.T. Guza, S. Elgar, and T.H.C. Herbers, Alongshore momentum balances in the nearshore, J. Geophys. Res., 103 , 15,667-15,676, 1998.

Freilich, M.H., and R.T. Guza, Nonlinear effects on shoaling surface gravity waves, Philos. Trans. R. Soc. London, Ser., A 311 , $1-41,1984$.

Gallagher, E.L. , B. Boyd, S. Elgar, R.T. Guza, and B.T. Woodward, Performance of a sonar altimeter in the nearshore, Mar. Geol., $133,241-248,1996$.

Gallagher, E.L., S. Elgar, and R.T. Guza, Observations of sandbar evolution on a natural beach, J. Geophys. Res., 103, 3203-3215, 1998.

Hallermeier, R., Oscillatory bedload transport: Data review and simple formulation, Cont. Shelf Res., 1, 159-190, 1982.

Hanes, D., and D. Huntley, Continuous measurements of suspended sand concentration in a wave dominated nearshore environment, Cont. Shelf Res., 6, 585-596, 1986.

Jaffee, B., and D. Rubin, Using nonlinear forecasting to determine the magnitude and phasing of time-varying sediment suspension in the surf zone, J. Geophys. Res., 101, 14,283-14,296, 1996.

Jumars, P., and A. Nowell, Fluid and sediment dynamic effects of marine benthic community structure, Am. Zool., 24, 45-55, 1984.

Lee, G., and W.A. Birkemeier, Beach and nearshore survey data: 1985-1991 CERC Field Research Facility, Tech. Rep. CERC. 93-3, Coastal Eng. Res. Cent., Vicksburg, MS, 1993.

Lippmann, T., and R. Holman, The spatial and temporal variability of sandbar morphology, J. Geophys. Res., 95, 11,575-11,590, 1990.

Madsen, O., Stability of a sand bed under breaking waves, paper presented at 14th International Conference on Coastal Engineering, Am. Soc. of Civil Eng., Copenhagen, 1974.

Nielson, P., Coastal Bottom Boundary Layers and Sediment Transport, 324 pp., World Sci., River Edge, N.J., 1992.

Osborne, P., and B. Greenwood, Sediment suspension under waves and currents: Time scales and vertical structure, Sedimentology, 40, 599-622, 1993.

Rakha, K., R. Deigaard, and I. Broker, A phase-resolving cross shore sediment transport model for beach profile evolution, Coastal Eng., 31, 231-261, 1997.

Roelvink, J., and M. Stive, Bar-generating cross-shore flow mechanisms on a beach, J. Geophys. Res., 94, 4785-4800, 1989.

Short, J., D. Sale, and J. Gibeaut, Nearshore transport of hydrocarbons and sediments after the Exxon Valdez oil spill, Am. Fish. Soc. Symp., 18, 40-60, 1996.

Thornton, E., R. Humiston, and W. Birkemeier, Bar-trough generation on a natural beach, J. Geophys. Res., 101, 12,097-12,110, 1996.

Trowbridge, J., and D. Young, Sand transport by unbroken waves under sheet flow conditions, J. Geophys. Res., 94, 10,97110,991, 1989.

Wright, D., J. Boon, S. Kim, and J. List, Modes of cross-shore sediment transport on the shoreface of the Middle Atlantic Bight, Mar. Geol., 96, 19-51, 1991.

S. Elgar, Woods Hole Oceanographic Institution, MS11, 266 Woods Hole Road, Woods Hole, MA 02543. (elgar@whoi.edu)

E. L. Gallagher, Department of Oceanography, 833 Dyer Road, Naval Postgraduate School, Monterey, CA 93943-5122. (elgallag@nps.navy.mil)

R. T. Guza, Center for Coastal Studies 0209, Scripps Institution of Oceanography, La Jolla, CA 92093-0209. (rtg@ coast.ucsd.edu)

(Received April 24, 2000; revised January 23, 2001; accepted February 16, 2001.) 